\title{
Yoga as an add-on treatment in the management of schizophrenia:
} a randomized controlled trial \author{
Jagadisha Thirthalli*1, Ganesan Duraiswamy¹, Shivarama Varambally¹, \\ Hongasandra Nagendra ${ }^{2}$ and Bangalore Gangadhar ${ }^{1}$
}

\begin{abstract}
Address: ${ }^{1}$ National Institute of Mental Health and Neuro Sciences, India and ${ }^{2}$ Swami Vivekananda Yoga Anusandhana Samsthana, India
\end{abstract}
* Corresponding author

from International Society on Brain and Behaviour: 2nd International Congress on Brain and Behaviour

Thessaloniki, Greece. 17-20 November 2005

Published: 28 February 2006

Annals of General Psychiatry 2006, 5(Suppl I):S84 doi:I0.II86/I744-859X-5-SI-S84

\begin{abstract}
Background
Despite the advent of typical and atypical antipsychotic drugs, outcome of schizophrenia has remained unsatisfactory. Alternative methods of treating schizophrenia are being studied. Yoga treatment has been shown to have anti-stress effect and is found to be useful in many psychiatric disorders. It has also been shown to be useful in schizophrenia in open-label studies (Lukoff, 1986), but randomized controlled studies are sparse.
\end{abstract}

\section{Materials and methods}

Sixty one patients (42 males; mean age: $31.6 \pm 7.8$ years) with a DSM-IV diagnosis of schizophrenia attending outpatient treatment at NIMHANS formed the sample. Most were chronically ill (median duration of psychosis: 60 months), moderately ill (mean CGI severity score: $5.0 \pm$ $0.84)$ and had no recent change in their medication. They were randomized into Yoga and physical exercise (PE) groups. Subjects in Yoga group were taught an integrated Yoga programme developed for positive health (Nagarathna and Nagendra, 2004) and those in PE group were taught stretching aerobic physical exercises. Subjects in both groups underwent supervised training in Yoga or PE for three weeks and practised the same at home for one hour everyday for four months. Subjects were assessed using the Positive and Negative Syndrome Scale (PANSS), Hamilton Depression Rating Scale (HDRS), Social and Adaptive Functioning Scale (SAFS), WHO Quality of Life Scale (WHOQOL-BREF) and Clinical Global ImpressionSeverity Scale (CGI-S) at baseline and after four months by a trained rater. The rater was blind to the group status of the subjects. Doses of antipsychotic medications were not changed during the four months of trial. Data was analysed using analysis of covariance with baseline scores as covariates. Forty one (67\%) completed the four month follow-up. These did not differ from those who dropped out on age, gender, duration of psychosis and baseline PANSS, HDRS, SAFS, WHOQOL-BREF and CGI-S scores.

\section{Results}

The two groups did not differ on any of the baseline parameters and antipsychotic dose. At the end of four months the subjects in Yoga group had shown greater improvement than those in the PE group in negative syndrome (F: 6.7; df: 1,38; $\mathrm{p}=0.01$ ), depression subscore (F: 8.5; df: 1,$38 ; \mathrm{p}<0.01)$ and anergia subscore (F: 4.6; df: 1,$38 ; \mathrm{p}=0.03$ ) of PANSS; HDRS total score (F: 10.7; df: 1,38; $\mathrm{p}<0.01$ ); SAFS total score (F: $5.5 ; \mathrm{df}: 1,38 ; \mathrm{p}=0.02$ ) and psychological quality of life (F: $7.8 ; \mathrm{df}: 1,38 ; \mathrm{p}<0.01$ ) after controlling for respective baseline scores.

\section{Discussion}

Using a randomized single-blind research design this study demonstrates that Yoga treatment is an useful addon treatment in schizophrenia. In particular, negative symptoms, depression and psychological quality of life tend to show differential improvement with Yoga treatment.

\section{References}

I. Lukoff D, Wallace CJ, Liberman RP, Burke K: A holistic program for chronic schizophrenic patients. Schizophr Bull 1986, I 2:274-282.

2. Nagarathna R, Nagendra HR: Integrated Approach of Yoga Therapy for Positive Health Second edition. Bangalore: Swami Vivekananda Yoga Prakashana; 2004. 